\title{
Dynamic Seals For High Speed Aircraft Gearbox
}

\author{
Hafeezur Rahman $A^{1}$, Junaid Basha A M ${ }^{2}$ \\ ${ }^{12}$ Scientists,Combat Vehicles R\&D Establishment (CVRDE), DRDO, \\ Ministry of Defence, Avadi, Chennai, India \\ e-mail: rahmanhafiz@ rediffmail.com
}

\begin{abstract}
The dynamic seals used for aircraft gearbox are of precision design and undergo stringent quality checks for obtaining clearance for aircraft fitment. These dynamic seals are capable of operating under severe environmental conditions with high reliability and very low leakage rate. In the present paper different types of rotary dynamic seals and their comparative performance for aircraft gearbox applications are discussed. Pressure diagram for a circumferential seal has also been presented along with factors to be considered during assembly of these seals. Finally a case study for a circumferential seal is presented and test results analyzed.
\end{abstract}

Key words: Dynamic Seals, Face Seals, High Speed Aircrafts

\section{INTRODUCTION}

Dynamic seals are intended to seal clearances between parts that have relative motion between each other. These seals find wide applications due to their lightweight, high reliability, long life and low frictional losses. Dynamic seals are extensively used for aircraft applications such as aircraft gas turbine main shaft seals, seals for auxiliary equipment and seals for transmission systems [1]. Transmission system for aircrafts consists of gearboxes to provide the starting torque to the main engine as well to provide power to run the accessories for aircraft operation. These gearboxes operate at very high speeds to the order of 20,000 rpm and hence necessitate an efficient lubrication system. The lubrication can be provided in two ways as from an external oil sump or an inbuilt oil sump within the gearbox. Both these modes require a perfect sealing system to ensure better performance of the gearboxes. For such high speeds and demanding requirements, carbon rotary dynamic seals are an ideal choice for designers as compared to normal rubber based seals. The present paper attempts to draw a comparison of the characteristics of various dynamic seals and their mode of sealing that gives an effective sealing system for an aircraft transmission system. A case study for a circumferential seal along with test results is also presented.

\section{TYPES OF ROTARY DYNAMIC SEALS}

The various types of rotary dynamic seals used in aircraft systems are as shown in Fig.1.

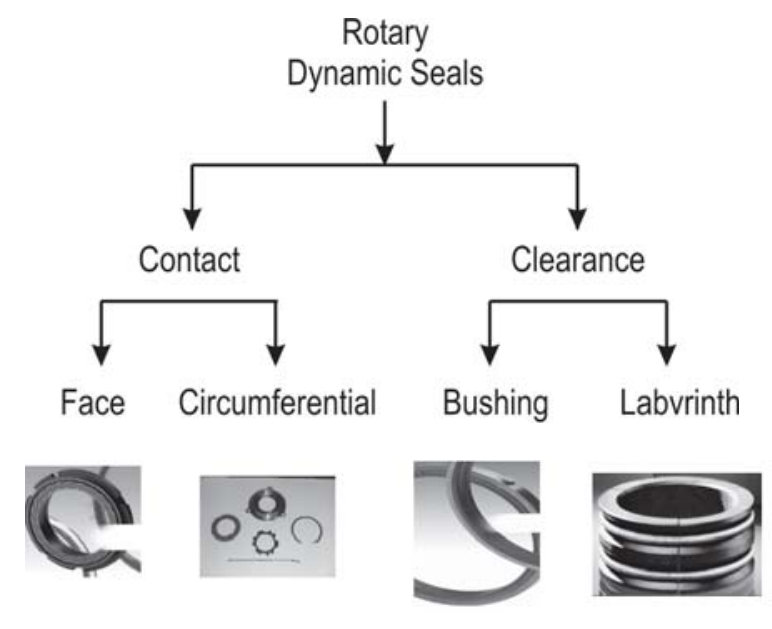

Fig. 1 Types of Rotary Dynamic Seals

In the high-speed application of aerospace gearboxes, mostly the face seals and circumferential seals are being used. These are being discussed as follows.

\section{A.Face seals}

Face seals as shown in the Fig.2 consists of a self aligning primary ring, a rigidly mounted mating ring, a secondary seal such as a ' $O$ ' ring that gives primary ring freedom to self align and set of springs to provide loading of seal faces [1]. The shaft-mounted face is flexibly mounted and sealed to the shaft so that the mating faces are held in contact in spite of shaft diameter variations. Sealing is accomplished by holding the two mating surfaces together by spring force and by fluid pressure acting on the rear of one of the sealing faces. The mating surfaces are lapped flat within 2-5 light bands. A certain amount of roughness is essential for the face seal to 
provide load bearing as exceedingly smooth finish results in failure of the seal [2].

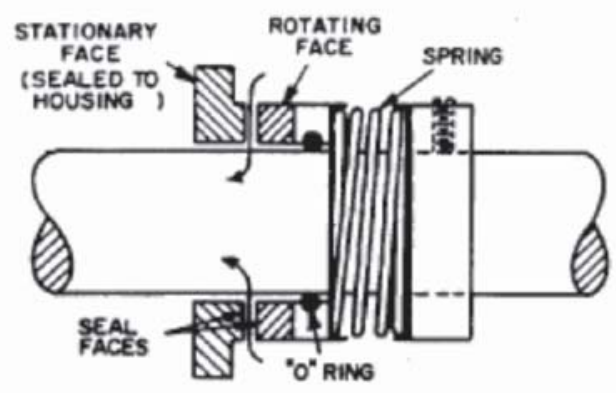

Fig.2 Face Seal

One of the essential features of face seals that have to be considered by the designer prior to its selection is the "balance " as it severely affects the operating pressure and temperature of the seals. Balance is the amount of fluid pressure acting on the rear of one of the sealing faces. There are two types of face seals, balanced and unbalanced seals as shown in Fig.3 (a) \& 3(b).
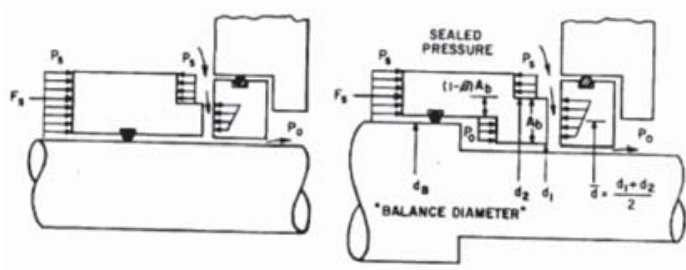

Fig 3 (a). Unbalanced Face Seal

Fig3 (b). Pressure Balanced Face Seal

The unbalanced seal as shown is the simplest form of seal with a annular ring fitted to a shaft of constant diameter. As a consequence, the contact area Ah between the sealing faces is equal to the area Ap on the rear of the sealing ring upon which the hydrostatic pressure of the fluid being sealed acts. The pressure limit for the sealing is reached when the forces on the seal head is sufficient to either blow open the seal or press the faces tight together to produce physical contact and boundary lubrication with the friction, heat release and wear. To overcome the pressure limitation of a few bars, a seal is balanced by using a stepped shaft as shown in the Fig. 3 (b). This reduces the loading on the seal faces resulting from the hydrostatic pressure Pp. The usual limit to balance is about one third, which means one third pressure is balanced leaving out two thirds of the hydrostatic pressure
Fp to act on the seal face as given (1). The hydrostatic pressure Fp is given by,

The effect of this balance is to increase the ability of the balanced face seal to seal pressures as high as 83 bar whereas an unbalanced seal would seal only upto a pressure of 13 bar.

\section{B. Radial Lift Circumferential Seals}

The radial lift seal as shown in Fig 4 consists of a annular ring similar to that of a face seal with a notable difference that sealing surfaces are in the circumferential direction. These seals are of sector type for the convenient assembly of the seal with the runner [3]. The sectors are kept in contact through a "garter" spring that imposes a load in the radial direction towards the shaft. The sectors are subjected to an axial load through sets of "compression" springs that tend to rub the sectors against the housing that incorporates the entire seal assembly. To prevent the sectors following the variations of the shaft diameter pins are provided in the housing that engage with the sectors [4].
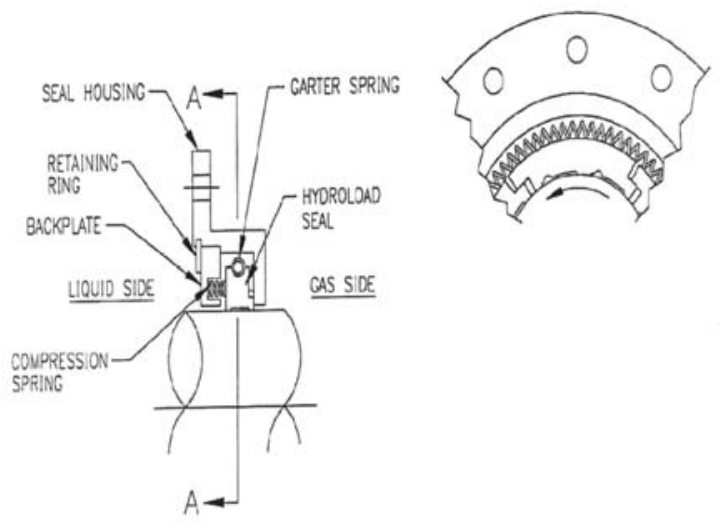

Fig 4. Circumferential Seal

These seals have a unique design feature of "negative" hydrodynamic lift so as to allow for a radial lift of the order of a few microns to reduce rubbing load and achieving pressure relief. This is done by incorporating "negative lift pockets" as shown in Fig.5 in the bore to effectively prevent "surf boarding" and makes the ring into a convenient and efficient seal for both oil and those involving solid oil. The radial lift seals are particularly sensitive towards direction of rotation of the shaft. Using a wrong direction of rotation for the seal would result in adverse leakage as it effectively prevents the entry of oil into the lifting pockets through the fluid scrapper [5]. 


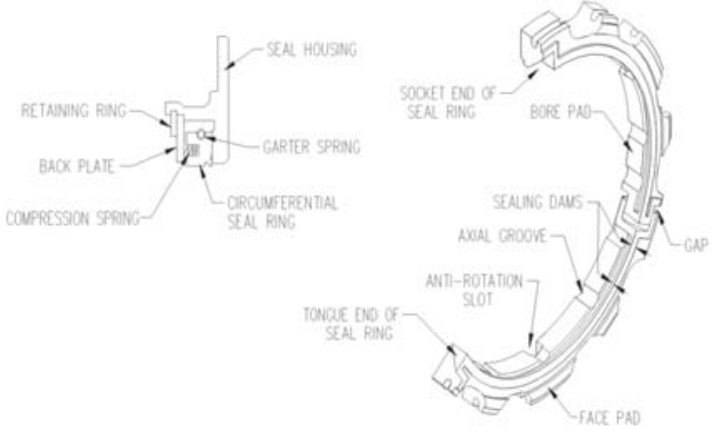

Fig 5. Sectors of Radial Lift Circumferential Seal

The basic principle behind the lifting concept is the variation in the pressure profile as shown in Fig.6 where three types of typical bearing shapes have been given as a simple taper, a compound taper and a stepped bearing. The upper surfaces of the bearings are subjected to ambient pressure $\mathrm{Po}$, the area of the depression shown on the pressure profile is the measure of the "negative lift" or the suction force per unit width [5].
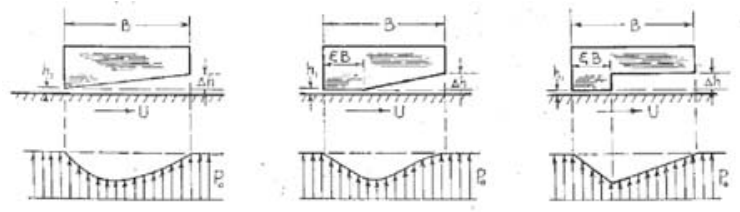

Fig 6. Simple Taper Compound Taper Stepped
Bearing

For the simple taper, the magnitude of the bearing force per unit width in the absence of side leakage is expressed in the following equation,

$$
\mathrm{W}=\frac{6 \mu \mathrm{U} \mathrm{B}^{2}}{\Delta \mathrm{h}^{2}}\left[\begin{array}{cc}
\frac{\ln (1+\alpha)}{\alpha} & -\underline{2} \\
\alpha & (1+2 \alpha)
\end{array}\right]
$$

With the stepped bearing the bearing force is given by

$\mathrm{W}=3 \mu \mathrm{UB}^{2}(1-\varphi) / \Delta \mathrm{h}^{2}$

The depth of these lift pockets severely affects the lift force the sectors effect upon the shaft. The higher the depth of the pocket, lesser will be the force that attains a cutoff where the pressure at the pocket equals the upstream pressure [6]. Considering the above, the force equilibrium for a typical circumferential seal used for sealing fluids is shown in Fig.7.

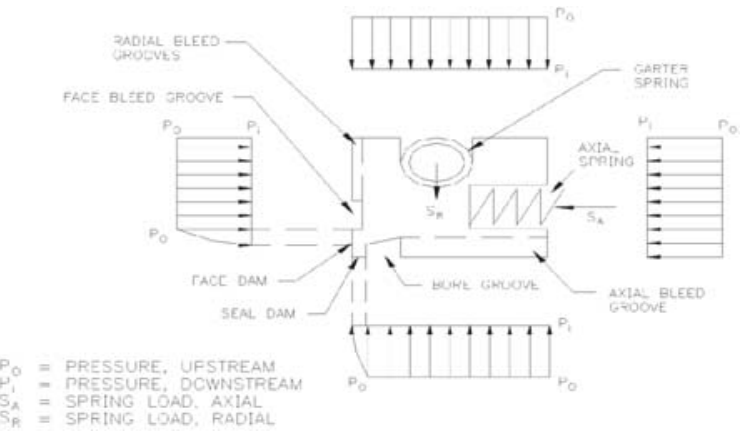

Fig 7. Force Equilibrium for a Circumferential Seal

The direct force due to oil pressure, spring force and lambda forces achieve axial force equilibrium whereas radial force equilibrium is achieved by direct force and hydrodynamic lift force as given in the following equations

$$
\begin{aligned}
& \mathrm{F}_{\mathrm{a}}=\mathrm{S}_{\mathrm{A}} \times \delta_{\mathrm{C}}+\mathrm{P}_{\mathrm{o}} \times \mathrm{A}_{\mathrm{fl}}-\mathrm{P}_{1} \times \mathrm{A}_{\mathrm{f}}-\lambda\left(\mathrm{P}_{\mathrm{o}}-\mathrm{P}_{1}\right) \mathrm{A}_{6} \\
& \mathrm{~F}_{\mathrm{r}}=\mathrm{P}_{1} \times A_{\mathrm{f}}+\mathrm{S}_{\mathrm{R}} \times \delta_{\mathrm{E}}+\mathrm{W}-\mathrm{P}_{1} \times \mathrm{A}_{\mathrm{f5}}-\lambda\left(\mathrm{P}_{\mathrm{o}}-\mathrm{P}_{1}\right) \mathrm{A}_{\mathrm{f}}
\end{aligned}
$$

\section{ROTARY CONTACT SEALS on a HIGH SPEED AIRCRAFT GEARBOX - A CASE STUDY}

This case study pertains to selecting rotary dynamic seals for a high-speed aircraft gearbox operating under a variety of environment conditions. The user specifications for a typical high speed aircraft gearbox is given in the following

$>$ Altitude ceiling : Upto $16 \mathrm{kms}$

$>$ Operating temperature : -54 to $+125^{\circ} \mathrm{C}$

$>$ Differential pressure : $0.65 \mathrm{bar}(\max )$

$>$ Direction of rotation : $\mathrm{CW} / \mathrm{CCW}$

$>$ Diameter range : 20 to $45 \mathrm{~mm}$

$>$ Runner speed : 5,000 to $21,000 \mathrm{rpm}$

$>$ Leakage

: Less than or equal to $4 \mathrm{cc} / \mathrm{hr}$

$>$ Life of seal : $2,000 \mathrm{hrs}$

$>$ Lubricating oil : MIL-PRF-23699F

$>$ Weight : Not to exceed $150 \mathrm{gms}$ perseal

$>$ Operating environment : Normal air/with salt fog

$>$ Lubrication sump : Inbuilt sump

Since in the present case, the lubrication sump is inbuilt, the primary factor to be considered is oil leakage. 
Excessive leakage may reduce the quantity of lube oil in the sump thereby reducing effective lubrication to the highspeed gears. The clearance seals have a high leakage rate of the order of $10 \mathrm{cc} / \mathrm{hr}$ as compared to contact seals having leakage rate of $4 \mathrm{cc} / \mathrm{hr}$ under level flight conditions. However, the clearance seals have a long operating life upto $1,00,000$ hours as compared to 60,000 hours for contact seals. However the clearance seals have excellent wear characteristics when compared to contact seals. However most of the aerospace gearboxes employ contact seals due to low leakage rate. Before selecting the type of contact seals, the material selection for the primary ring of the contact seal would be the most important design criterion. The important factors in selecting materials for the primary ring would be compatibility, high temperature resistance, corrosion resistance and strength. Taking these factors into account three materials that are commonly used in contact seals are carbon graphite, leaded bronze and PTFE. For aircraft gearbox applications weight of the seal has to be as low as possible and seals are to be free from coking, carbon blistering and should not generate abrasive materials. Considering the conditions carbon graphite is found to be the good choice due to its low density and inherent quality of selflubrication best suited for aerospace applications. Also it is inert to attacks from the operating environment conditions. Carbon graphite is available in a variety of combinations alloyed with Babbitt, Copper, Antimony, Silver and Lead and in resin-impregnated forms [7]. To choose between face and circumferential seals we have to consider the characteristics and manufacturing cost as given in Table 1.

Table 1. Comparison of Face and Circumferential seal

\begin{tabular}{|l|c|c|}
\hline \multicolumn{1}{|c|}{ Parameter } & Circumferential & Face \\
\hline Shaft speed m/sec & 183 & 153 \\
\hline Temperature ${ }^{\circ} \mathrm{C}$ & 540 & 540 \\
\hline $\begin{array}{l}\text { Pressure in bar } \\
\text { (Unbalanced) }\end{array}$ & 5.86 & 12.06 \\
\hline $\begin{array}{l}\text { Weight in gms } \\
\text { (Dia 40 mm) }\end{array}$ & 145 & 170 \\
\hline Axial shaft movement & Unlimited & Restricted \\
\hline $\begin{array}{l}\text { Cost per unit (same } \\
\text { dia \& speed) }\end{array}$ & $\mathrm{x}$ & $3 \mathrm{x}$ \\
\hline
\end{tabular}

\section{A. Final Selection of Seal For Aircraft Gearbox:}

Considering all the above factors, finally a circumferential rotary seal is considered for a typical aircraft gearbox. This gearbox forms the part of the Secondary Power System (SPS) of the aircraft coupled to the engine gearbox serving twin purposes. First to start the main aircraft engine through the engine gearbox and secondly to run the accessories mounted on it. Thus the gearbox supplies both hydraulic and electrical power to the aircraft. Totally five dynamic circumferential seals, one at the input drive and other four on the output drive pads are assembled on the gearbox as shown in Fig.8.

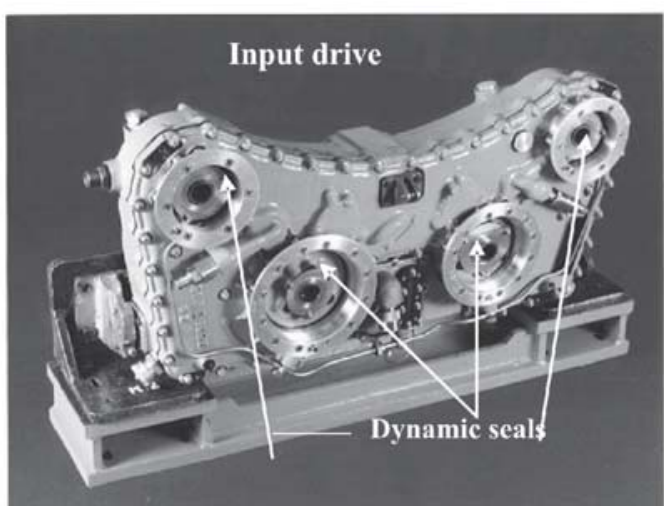

Fig 8. Dynamic Seals Assembled On Aircraft Gearbox

The test rig used for certifying the seals consist of a housing with a shaft assembly on which the test seal shall be mounted as shown in Fig.9.

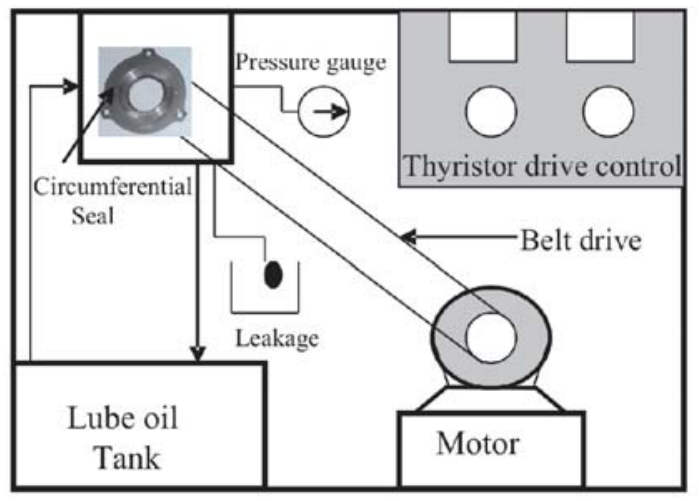

Fig 9. Dynamic Seals Test Rig

The standard shaft used for testing the seal is hard chrome plated and geometrical tolerances are maintained within 5 microns. A gear pair, which in turn is connected to a pulley, runs this shaft, drive to a variable speed motor controlled through a thyristor drive. Test results consist of static leakage and dynamic leakage test on the test rig as given in Table2. Static leakage test consists of subjecting the seal to partial and full flooding conditions. Dynamic leakage test consists of $25 \mathrm{hrs}$ of Performance test with shaft speed of $17000 \mathrm{rpm}$. 
Table 2. Leakage Through Circumferential Seals (at Test Rig Conditions)

\begin{tabular}{|c|l|c|}
\hline $\begin{array}{c}\text { SI } \\
\text { No }\end{array}$ & \multicolumn{1}{|c|}{ Type of Test } & $\begin{array}{c}\text { Leakage in } \\
\mathbf{c c / h r}\end{array}$ \\
\hline 1 & $\begin{array}{l}\text { Static leakage test at 1 bar } \\
\text { (Fully flooded condition) }\end{array}$ & 0.66 \\
\hline 2 & $\begin{array}{l}\text { Dynamic leakage test at 0.65 } \\
\text { bar/17000 rpm } \\
\text { (With air oil mist / partial } \\
\text { flooding) }\end{array}$ & 2 \\
\hline
\end{tabular}

With five circumferential seals assembled on the drive pads of the gearbox, a performance record test at various speeds and loading conditions have been carried out as shown in Fig.10.

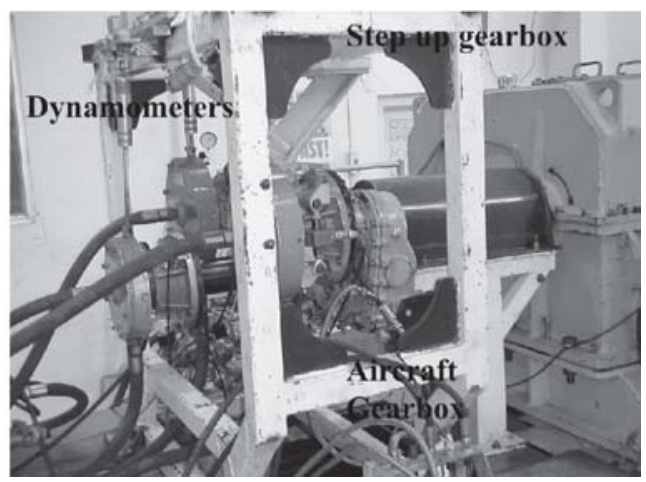

Fig 10. Performance Record Test Rig

The gearbox as installed on the test rig is subjected to a Performance record test which consists of 25 cycles with speed ranging from $9100 \mathrm{rpm}$ to $16800 \mathrm{rpm}$ with 5 minutes dwell time for each speed and the overall cycle time of one hour for each cycle. The gearbox is loaded by means of water brake dynamometers simulating the load requirements of the accessories mounted on the gearbox in the aircraft. The drive for the gearbox is through a DC Motor and a Step up gearbox. The leakage observed on the gearbox for 25 cycles of Performance record test is between $0-3 \mathrm{cc} / \mathrm{hr}$.

\section{CONCLUSION}

Different types of rotary dynamic seals have been discussed and their characteristics compared. The contact seals have lower leakage rate as compared to clearance seals. However the life and friction characteristics are better in the case of clearance seals. Although the shaft speed and temperature conditions are comparable, the face seal has more pressure withstanding capacity than circumferential seal. But the cost of a face seal is thrice as that of circumferential seal and the weight and assembly restrictions offers certain restrictions for the use of face seals. Hence in most of the cases, high-speed aircraft transmission gearboxes employ circumferential contact seals.

A typical aircraft gearbox with five rotary contact circumferential seals has been taken to study the leakage rate through a pre-performance test and 25 cycles of performance record test. The static leakage test results are well within the specifications taken for consideration. Further the number of cycles of Performance Record Test in different speed conditions recorded very low leakage rate ranging from $03 \mathrm{cc} /$ hour. This justifies the selection of circumferential seal for aircraft application. Since the loss of oil through the gearboxes during long hours of flight to be minimized, therefore in most of the aircraft applications the circumferential seals are used.

\section{NOMENCLATURE}

$A_{p} \quad$ Area of primary seal face in $\mathrm{mm}^{2}$

$A_{f 1}$ Area of upstream axial seal face in $\mathrm{mm}^{2}$

$A_{t 2}$ Area of downstream axial seal face in $\mathrm{mm}^{2}$

$A_{13} \quad$ Area of seal dam axial face in $\mathrm{mm}^{2}$

$\mathrm{A}_{i 4}$ Area of upstream radial seal face in $\mathrm{mm}^{2}$

$A_{i 5}$ Area of downstream radial seal face in $\mathrm{mm}^{2}$

$A_{16}$ Area of seal dam radial face in $\mathrm{mm}^{2}$

$B$ Bearing length in the direction of motion in $\mathrm{mm}$

$F_{p}$ Hydrostatic pressure force on the seal face in $\mathrm{N}$

$F_{a} \quad$ Net axial force acting on seal in $\mathrm{N}$

$F_{r} \quad$ Net radial force acting on seal in $\mathrm{N}$

$\mathrm{h}$ Mean clearance between the seal faces in $\mathrm{mm}$

$P_{p} \quad$ Net hydrostatic pressure of fluid being sealed $P s$ Po) in bar

$P_{0}$ External, ambient pressure in bar

$P_{s} \quad$ Internal pressure in bar

$\mathrm{d}_{1}$ Inside diameter of the seal in $\mathrm{mm}$

$\mathrm{d}_{2} \quad$ Outside diameter of the seal in $\mathrm{mm}$

$d_{s} \quad$ Mean diameter of the seal in $\mathrm{mm}$

$\mathrm{U}$ Relative velocity of boundaries of the bearing in $\mathrm{m} / \mathrm{sec}$ 
a Ratio of clearance at entry to the difference in clearances at entry and exit

$\beta \quad$ Balance ratio

$\mu \quad$ Fluid viscosity in $\mathrm{Ns} / \mathrm{m}^{2}$

$\varphi \quad$ Ratio of length of entry section to total length for stepped bearing

$\wedge$ Ratio of upstream to downstream pressure

\section{REFERENCES}

[1] CRC Press LLC, 1997 "Tribology data handbook"

[2] P.C.Stein, March 1961 "Adiscussion on the theory of sealing devices" SAE Southern England Section
[3] P.C.Stein, "Circumferential seals for use as oil seals" 33rd Annual meeting of ASLE, Michigan

[4] P.C.Stein, October 1979 "Runners for circumferential seals requirements and performance" ASLE/ASME Conference, Ohio

[5] P.C.Stein,"Circumferential shaft seal" U.S Pat no: 2908516

[6] P.C.Stein,"Seal for sealing between a rotating member and a housing" U.S.Pat No: 4082296

[7] Ferlinard.L.Vogel, "Intercalated graphite gaskets| and pressure seals" U.S.Pat No: 4406466 